
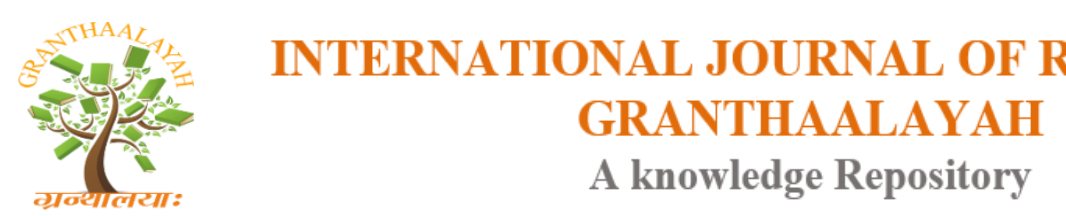

Science

\title{
THE USE AND PERCEIVED IMPACT OF MOBILE COMMUNICATION TECHNOLOGY (MCT) IN BOTSWANA COMMERCIAL FARMING
}

\author{
Thato Mcnulty Pholele ${ }^{1}$, Moakofhi Kago Moakofhi², Tawona Vanessa Phiri ${ }^{3}$, Oratile \\ Leteane $^{4}$ \\ 1,2,3,4 Department of Basics Sciences, BUAN, Botswana
}

DOI: https://doi.org/10.29121/granthaalayah.v5.i6.2017.2018

\begin{abstract}
There has been rapid development of mobile communication technology (MCT) in the last decade with Botswana having a tele density of $168 \%$, hence the need to find out if MCT is effectively used in agriculture. A sample of 36 commercial farmers answered a questionnaire. All commercial farmers in the study own at least one form of MCT device, the most common being mobile phone. In spite of ownership of such devices, commercial farmers do not adequately use MCT in their farm work as on average $53 \%$ said they have used it in one form or another. The perceived impact of MCT in commercial farming is also not satisfactory as on average $50 \%$ of the farmers in the sample answered in the negative. The unsatisfactory use of MCT by farmers can be mitigated by having discussions with farmers and showing them the benefits of using MCT in their farm work.
\end{abstract}

Keywords: ICT; Commercial Farming; Agricultural Technology; Mobile Communication.

Cite This Article: Thato Mcnulty Pholele, Moakofhi Kago Moakofhi, Tawona Vanessa Phiri, and Oratile Leteane. (2017). "THE USE AND PERCEIVED IMPACT OF MOBILE COMMUNICATION TECHNOLOGY (MCT) IN BOTSWANA COMMERCIAL FARMING." International Journal of Research - Granthaalayah, 5(6), 202-210. https://doi.org/10.29121/granthaalayah.v5.i6.2017.2018.

\section{Introduction}

Agriculture is one of the first means of gainful production known to human kind. It has been used by many people in different countries across the world as a source of employment, particularly source of food. Many African countries including Botswana relied heavily on agriculture related activities for sustenance before and around independence. The contribution of Agriculture in many countries gross domestic product (GDP) including Botswana has however reduced over the years. The contribution of agriculture in Botswana GDP was around 40\% at independence (1966) and reduced to $4 \%$ in 2003 (Moorhead, 2005). It fell further to 1.9\% in 2008. This implies that agriculture is not producing as much as it should. The drop in agricultural 
sector contribution could also be due to the fact that, other sectors like mining and tourism became more active. Since agriculture has over the years been proven to be a possible source of massive employment, and also an important sector of the economy as countries need to feed its citizens, there is a need to find out how technology, particularly mobile communication technology (MCT) can improve farming.

\subsection{Agriculture in Botswana}

Botswana is a land locked Southern African country with a population of around 2 million. Its climate varies from semi-arid to semi-tropical. The rainy season is short and mainly between November and January (Statistics Botswana, 2013). The agriculture sector in Botswana is dominated by livestock farming.

Cattle population fluctuated around 2 million between 2003 and 2013. Cattle population grew past 2 million in 2006 and then fell below this figure in 2012. The goats population rose from a figure of around 1.4 million in 2003 to around 1.9 million in 2010. The population of goats then went down to around 1.5 million in 2013.The population of sheep on the other hand fluctuated from around 200 thousand in 2003 to around 250 thousand in 2013. Statistics Botswana (2013) revealed that the traditional sector mainly planted sorghum, maize, millet and beans. For all the years reviewed from 2003 to 2013, the area planted was always greater than area harvested.

Data from Statistics Botswana (2013) for a period from 1979 to 2013 generally indicate that the commercial cattle farming performed better compared to traditional farming when it came to death rates and off-take rates whereas birth rates where very comparable. The commercial sector continuously registered low death rates and high off-take rates compared to the traditional sector.

\subsection{Telecommunication in Botswana}

Telecommunication through radio broadcasting has been used over the years to provide information on ways of improving farming across the world including Botswana. Radio Botswana started broadcasting in 1961, and one of its core functions was to encourage efficient farming. Botswana Television (BTV) also had farming programs aired from its inception, augmenting the voice broadcast through radio. BTV was established in year 2000 (Department of information and Broadcasting, 2016).Television although not accessed by many farmers compared to radio has the advantage of pictures which make demonstrations easy to follow.

Telecommunication through landline phones was introduced in Botswana by Botswana Telecommunication Corporation (BTC). BTC was established in 1980 by an Act of Parliament (BTC Act) to provide, develop, operate and manage Botswana's national and international telecommunications services (BTCL, 2016). BTC (now Botswana Telecommunication Limited $(\mathrm{BTCL})$ ) has since been partly privatized as the government currently holds $51 \%$ whereas the other $49 \%$ is privately owned. Botswana liberalized her telecommunication industry in 1998 (Lesitaokana, 2013). Mascom Wireless and Orange Botswana (then Vista) were the first two private mobile communication operators. Be Mobile, which is a BTCL mobile network operator was introduced in 2008 (BTCL, 2016). 
Mobile network coverage for the three networks in Botswana has increased over the years to cover at least $95 \%$ of the population with varying network capabilities of $2.5 \mathrm{G}, 3 \mathrm{G}$ and $4 \mathrm{G}$. This coverage has been matched by very high mobile subscriptions. The mobile subscriptions increased from 3,204,869 in March 2014 to 3,405,887 in March 2015. Teledensity on the other hand grew from 158\% in March 2014 to $168 \%$ in March 2015 (BOCRA, 2015).

The introduction of these three modes of telecommunication which is radio, television and telephones has provided means of efficient communication that can be used to improve farming. There is a need to find out what mobile communication devices farmers have. We need to also find out if these devices are used in farming activities.

\subsection{Mobile Communication Technology in Agriculture}

Mobile communication technologies (MCT) are devices that are used for communication and have the capacity of being used while in motion. These include mobile phones, ipads and lap tops. Mobile communication technology has impacted quite positively in people's lives as it has significantly reduced communication cost. This is due to the fact that MCT can be used in real time while stationary or in motion, provided there is network coverage in the area of use.

The high mobile network coverage and teledensity in Botswana provides an opportunity for growth in agriculture. Literature indicates that MCT has been used to grow and improve agriculture. Radio and mobile phones have been used in Kenya to create a platform for discussion on matters related to agriculture. In this format called FrontlineSMS, farmers send text messages to a radio host who then later hosts a radio discussion on the matters raised by farmers (Banks, 2011).

The markets for farming products have adopted MCT to communicate with their potential clients. Botswana Meat Commission for instance shares information about cattle pricing with farmers through mobile phone technology and internet (Mahabile, 2013). Other than information on market prices, MCT may also be used to provide information on weather, transport and agricultural techniques via voice, short message service (SMS), radio and internet (Aker, 2011; Gakuru et al., 2009). Farming is a process hence requires information on different stages. This information includes weather forecasts, pest attacks, inputs, cultivation practices, pest and disease management and prices. Bertolini (2004) observes that the 'telephone is the only ICT used (if any) by the majority of farmers in Africa'. Some of the respondents in the study conducted by Bertolini considered cellular phone applications, such as the Short Message Service (SMS), to be one of the most important emerging ICT applications in Africa.

MCT helps in reducing costs as farmers may gather information on the markets by calling or browsing through the websites of the market. This takes away the need to travel long distances hence reduce transportation costs and saves time for farmers (Maumbe, 2010; de Silva and Dimuthu Ratnadiwakara). MCT also has the capability of supporting money transfer which allows farmers to perform money transections in their farms (Foster and Rosenzweig, 1995; Foster and Rosenzweig 2010). 
Farmers who used MCT in India reported a diverse set of benefits including yield improvements, price realisation and increased revenues through better adjustment of supply to market demand. They also indicated that the use of MCT may results in improved access to information which brings about better seed variety selection, best cultivation practices, protection from weatherrelated damage, improved handling of plant disease and optimum price realisation (Mittal et. al., 2010).

Extension services have for many years relied on extension workers travelling long distances to meet farmers and advise them on productive farming. This tended to take time and had high transportation costs. The advent of MCT has made it possible for farmers to interact with extension workers timeously (Gakuru, 2009; Van Audenhove, 2003, Guislain et al., 2006). MCT may also be used to gather information on both farmers and extension workers there by improving efficiency and accountability (Dillon, 2011). This is possible because extension workers visits may be verified by calling farmers. Information gathered from farmers may be used for research hence find ways of improving farming.

\section{Methodology}

The study was based on a survey strategy and it comprised of both descriptive and analytical methods. Data collection was done through a questionnaire. This study was conducted in the south eastern region of Botswana. The region around the capital city Gaborone has abundant waste water that can be used for irrigation. The study covered commercial farmers around Gaborone being Tlokweng, Glen Valley, Boatle and Kopong. The questionnaire had three parts. The first part was on demographics, whereas the second part was on use of MCT by farmers in their farming activities, and the third part was on perceived impact of MCT in agriculture. The data collected was analyzed using frequencies, percentages, means and standard deviation. Some of this data has been presented using tables and bar charts.

\section{Results, Analysis and Discussion}

The study had a sample of 50 farmers who were contacted to answer the questionnaire and thirty six successfully answered it. Of the thirty six respondents, $63.9 \%$ were male whereas $36.1 \%$ were female. This corroborates Anasoki and Fasona (2004) findings that more men than women tend to engage in commercial farming. The majority of the respondents aged between 41 to 50 years formed $47.2 \%$ of the sample followed by age range of 31 to 40 with $33.3 \%$. The next age range was 20 to 30 with $13.9 \%$ and lastly those above 50 years with $5.6 \%$.

Most of the respondents had farm experience of 6 years to 10 years at $38.9 \%$ followed by 11 years to 15 years with $36.1 \%$. Respondents with experience less than five years were $13.9 \%$ of the sample, whereas 15 to 20 years and above 20 years were each $5.6 \%$ of the sample. This indicates that people are beginning to use commercial farming as a means of gainful employment particularly that the government of Botswana has some programmes that encourage it. These programmes include Integrated Support Programme for Arable Agriculture Development (ISPAAD) which was introduced in 2008 to address challenges facing arable farmers. The components of ISPAAD include: provision of draught power, potable water, seeds, fertilizers and herbicides, facilitation of access to credit and fencing and establishment of agricultural 
service centres. In ISPAAD, farmers are categorised and subsidised according to the area of production and level of operation. Commercial farmers who cultivate over 150 hectors are subsidised at 30\%. Another programme which encourages and improves farming is Livestock Management and Infrastructure Development (LIMID) (Ministry of Agriculture, 2016).

The study revealed that, most of the respondents had completed O' Level (high school) at $47.2 \%$ of the sample followed by tertiary with $41.7 \%$. Only $11.1 \%$ had completed junior high school. The sample collected had $72.2 \%$ of the respondents as arable farmers, $8.3 \%$ pastoral, $2.7 \%$ mixed farming and, $2.7 \%$ ornamental farming. The high number of arable farmers around Gaborone, the capital city of Botswana is due to the good infrastructure, proximity to markets and available programmes like ISPAAD and Citizen Entrepreneurial Development Agency (CEDA). CEDA has an agricultural division called agribusiness. Agribusiness loans from CEDA are accessed by citizens aged 18 years and above. The loan limit is P500.00 to P30 million (CEDA, 2016).

Table 1: Type of MCT device owned by commercial farmers

\begin{tabular}{|c|c|c|c|c|c|}
\hline Lap top & Tablet & $\begin{array}{c}\text { Mobile } \\
\text { phone }\end{array}$ & $\begin{array}{c}\text { Wireless } \\
\text { debit }\end{array}$ & $\begin{array}{c}\text { Payment } \\
\text { terminal }\end{array}$ & $\begin{array}{c}\text { Note book } \\
\text { computer }\end{array}$ \\
\hline $47.2 \%$ & $19.4 \%$ & $100 \%$ & $8.3 \%$ & $0 \%$ & $22.2 \%$ \\
\hline
\end{tabular}

The results presented in Table 1 show that commercial farmers own or use several MCT devices. The most common device is the mobile phone with $100 \%$ followed by lap top with $47.2 \%$ of the respondents. All commercial farmers in the sample do not own payment terminals. The high number of mobile phone ownership is consistent with the BOCRA (2016) report which indicated that the mobile teledensity in Botswana was 168\%. Bertolini (2004) has also found telephones as one ICT device mainly used by the majority of farmers in Africa.

Commercial farmers were asked several statements to establish the type and degree of use of MCT devices in their work. The statement listed and numbered (I) to (IV) below all had five answer levels as $1=$ Never, $2=$ Sometimes, $3=$ Often, $4=$ Mostly, and $5=$ extremely. The analysis of these five statements is in Table 2.

I. To what degree do you access information on agricultural programmes and services like LIMID, ISPAAD and artificial inseminations seminars, farmers and Ministry of Agriculture workshops using MCT devices?

II. How often do you use MCT devices to download information on farm related activities like weather reports and forecasting, livestock feeds, livestock diseases, veterinary medicine, type of plants and crops to plough fertilizers etc.?

III. How often have you increased income in farming, by borrowing money from banks, sending money and lending money to other people using MCT devices?

IV. To what degree have you used MCT devices to research on new best agricultural practices which suit the particular farming you practice E.g. use of automation to feed and water plants using MCT Devices?

$\mathrm{V}$. To what degree have you used MCT device to market your farm products to the market? 
Table 2: Uses of MCT in commercial farming

\begin{tabular}{|c|l|l|l|l|l|l|l|}
\cline { 4 - 8 } \multicolumn{2}{c|}{} & \multicolumn{5}{c|}{ Response in percentage (\%) for each level } \\
\hline Statement & Mean & $\begin{array}{l}\text { Standard } \\
\text { deviation }\end{array}$ & $\mathbf{1}$ & $\mathbf{2}$ & $\mathbf{3}$ & $\mathbf{4}$ & $\mathbf{5}$ \\
\hline I & & & & & & \\
\hline II & 1.94 & 0.667 & 58.5 & 8.3 & 13.9 & 19.4 & 0 \\
\hline III & 1.69 & 0.680 & 50 & 19.4 & 11.1 & 16.7 & 2.7 \\
\hline IV & 0.727 & 44.4 & 41.7 & 13.9 & 0 & 0 \\
\hline V & 1.67 & 0.735 & 47.2 & 27.8 & 13.9 & 5.6 & 5.6 \\
\hline
\end{tabular}

The results in Table 2 show that commercial farmers do not adequately use MCT devices to carry out some important activities in their farm work as evidenced by means for all statements which are mostly for negative statements. Most commercial farmers (58.5\%) have never used MCT to access information on agricultural programmes and services provided by the government. This could mean that farmers still favour other media to source information. Fifty percent of the respondents said they never used MCT devices to download information on weather reports, livestock feeds, livestock diseases, veterinary medicine, type of plants, fertilizers and related information. The number of commercial farmers who have never used MCT to perform financial transactions is fairly high at $44.4 \%$. A significant number of commercial farmers have indicated that they have never used MCT to research on new best agricultural practices. Even more worrying is the fact that $63.9 \%$ of the sample indicated that they have never used MCT to market their farm products. This brief discussion show the need to encourage farmers to embrace MCT in their farming activities as it has been proven elsewhere to improve farming (Banks, 2011; Aker; Gakuru et al., 2009; Van Audenhove 2003, Guislain et al., 2006).

Respondents were asked to indicate their perceived impact of use of MCT devices on their farms. The statements which were used to measure perceived impact were;
A. Ease workload on workers.
B. Recording of information made easy.
C. Less manpower needed.
D. Improved communication.

The results which show perceived impact are shown in Fig. 1. These results are presented using percentage of the thirty six respondents for each statement.

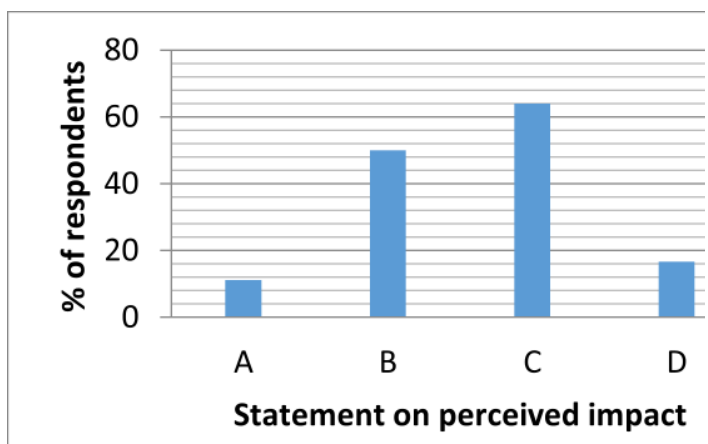

Figure1: Perceived impact of MCT in commercial farming 
A low percentage of the thirty six respondents (11.1\%) believed that ever since they used MCT devices (statement A), the work load on workers in their farms reduced. This could be that the respondents were not aware that the use of MCT could reduce the need to travel in order to communicate or source information. A fairly high number of respondents indicated that the use of MCT in their farms had made recording of information easy (Statement B). Mobile communication devices make it possible for users to carry them to any point in the farm and recording of information can be done on the spot. Statement $\mathrm{C}$ had $63.9 \%$ of respondents agreeing with. Farmers believe ever since they started using MCT devices there has been less manpower needed. The use of mobile communication devices reduce the need to travel hence less manpower is needed. Farmers may also carry certain functions in their farms like research on farm related matters, perform financial transactions hence may not need a lot of manpower to assist. This is consistent with the finding by Maumbe (2010), Harsha de Silva and Dimuthu Ratnadiwakara who established that the use of MCT may reduce transportation costs and save time for farmers. A few farmers (16.7\%) observed that the introduction of MCT has improved communication (statement D) hence made farming easy and enjoyable.

The study further solicited commercial farmer's perceptions on farm achievements since the use of MCT. All respondents were asked to tick statements which they believe spoke to their achievements. These statements were;

E. Increase in production.

F. Increase in annual income.

G. Reduces spending on man-power.

H. Ecological benefits such as reducing use of paper-work hence less littering.

The results of the respondent's perceived achievements are shown in Fig. 2.

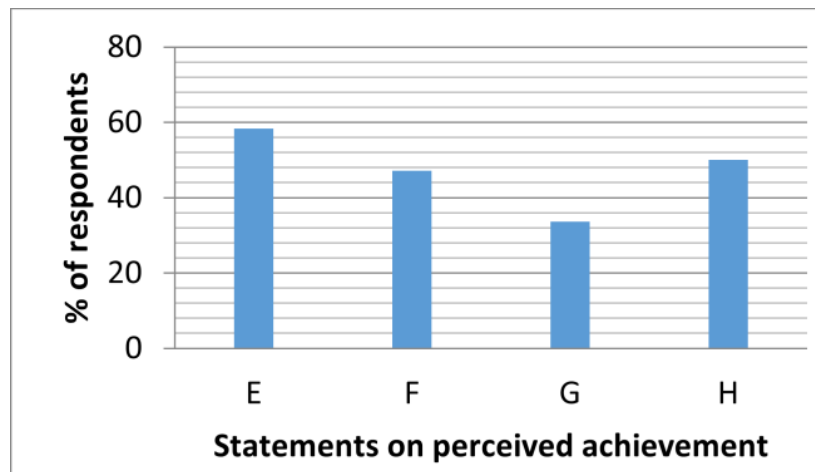

Figure 2: Perceived achievements in commercial farming due to MCT.

Commercial farmers were not very enthusiastic about their achievements in farming as a result of their use of MCT, none the less, 58.3\% believed that the use of MCT in their farming had contributed in increase in production (Statement E). On the other hand, 47.2\% thought the use of MCT brought about increase in annual income (F). Statement G (reduces spending on manpower), had $33.6 \%$ of commercial farmers agreeing with. The farmers who agreed with statements E and F are consistent with the findings by Mittal et al. (2010) that use of MCT may result in yield improvements, price realisation and increased revenues through better adjustment of supply to market demand. The study revealed that $50 \%$ of farmers believed that the use of 
MCT elicited ecological benefits such as reducing use of paper-work hence less littering (statement $\mathrm{H}$ ).

\section{Conclusion}

This study established that more male farmers engage in commercial farming around Gaborone, the capital city of Botswana. Commercial farming in this region is mainly arable due to availability of waste water from the city. The sample which was considered was dominated by fairly new entrants in the farming sector with experience of 6 to 15 years. This could be attributed to government programmes like ISPAAD, LIMID and CEDA which were recently introduced to encourage farming. All commercial farmers in the sample had mobile phones, which is consistent with the country's teledensity of $168 \%$. The results from the study indicate unsatisfactory use of MCT devices in farming. An average of $53 \%$ of commercial farmers said they had never used MCT to access government programmes, research on agriculture related matters, accessed financial services and reached markets. Further, the minimum use of MCT in farming brought with it perceived less impact of MCT in agriculture. These negative perceptions on impact of MCT in agriculture can be reduced by teaching farmers on how to access information using MCT, and its general usefulness. This would go a long way in improving farming and could at the same time attract large number of youth hence significantly reduce the number of the unemployed.

\section{References}

[1] Jenny C. Aker (2011). "Dial "A" for Agriculture: A Review of Information and Communication Technologies for Agricultural Extension in Developing Countries." Center for Global Development, 1-37.

[2] Vide Anosike and Mayowa Fasona. (2004). "Gender Dimensions of Urban Commercial Farming in Lagos, Nigeria." Urban Agriculture magazine, 27-28.

[3] Goyal Aparajita. (2010). Information, Direct Access to Farmers, and Rural Market Performance in Central India." American Economic Journal: Applied Economics, 2(3), 22-45. DOI: 10.1257/app.2.3.22.

[4] Ken Banks. (2011). “"Farming Out” Agricultural Advice Through Radio and SMS". http://voices.nationalgeographic.com/2011/04/26/\%E2\%80\%9Cfarming-out\%E2\%80\%9Dagricultural-advice-through-radio-and-sms/.

[5] Romeo Bertolini. (2004). "Strategic Thinking: Making Information and Communication Technologies Work for Food Security in Africa." International Food Policy Research Institute. https://ageconsearch.tind.io/record/45768/files/ib27.pdf

[6] BOCRA. (2015). "BOCRA Annual Report 2015." 1-84. http://www.bocra.org.bw/sites/default/files/documents/BOCRA\%20Annual\%20Report\%202015 $\% 20$ Web.pdf.

[7] BTCL. (2016). http://www.btc.bw.

[8] CEDA Agribusiness. (2016). http://www.ceda.co.bw/agribusiness.

[9] Harsha de Silva and Dimuthu Ratnadiwakara.(2008). "Using ICT to reduce transaction costs in agriculture through better communication: A case-study from Sri Lanka." http://www.lirneasia.net/wp-content/uploads/2008/11/transactioncosts.pdf

[10] Department of information and Broadcasting (2016). http://www.dib.gov.bw/.

[11] Brian Dillon. (2011). "Using mobile phones to collect panel data in developing countries." Journal of International Development, 518-527. DOI: 10.1002/jid.1771. 
[12] Andrew D. Foster and Mark Rosenzweig. (2010). "Microeconomics of Technology Adoption." Annual Review of Economics, 2, 395-424. https://doi.org/10.1146/annurev.economics.102308.124433.

[13] Andrew D. Foster and Mark Rosenzweig. (1995). "Learning by Doing and Learning from Others: Human Capital and Technical Change in Agriculture." Journal of Political Economy, 103(6), 1176-1209. http://www.journals.uchicago.edu/doi/abs/10.1086/601447.

[14] Mucemi Gakuru, Kristen Winters and Francois Stepman. (2009). "Innovative Farmer Advisory Services Using ICT.” IST-Africa 2009 Conference Proceedings.1-11.

[15] Pierre Guislain, Christine Zhen-Wei Qiang, Bruno Lanvin, Michael Minges, and Eric Swanson. (2006). "Overview In 2006 Information and communications for development: global trends and policies." World Bank, Washington, 1-23.

[16] William O. Lesitaokana. (2013). "Key issues in the development of mobile telephony in Botswana (1998-2011): An empirical investigation." New Media \& Society. 1-16. http://journals.sagepub.com/doi/abs/10.1177/1461444813495161.

[17] Mahabile, M. (2013). "Measuring transaction costs in marketing cattle in Southern Botswana: A case study." Botswana Journal of Agriculture and Applied Sciences (BOJAAS), 9(2), 75-81.

[18] Blessing M. Maumbe and Julius Okello. (2013). "Uses of Information and Communication Technology (ICT) in Agriculture and Rural Development in Sub-Saharan Africa: Experiences from South Africa and Kenya." International Journal of ICT Research and Development in Africa (IJICTRDA), 113-132. DOI: 10.4018/978-1-4666-3607-1.ch009.

[19] Botswana Ministry of Agriculture, LIMID Forms, (2016). http://www.moa.gov.bw/.

[20] Botswana Ministry of Agriculture, ISPAAD Guidelines, (2013). http://www.moa.gov.bw/downloads/ISPAAD_guidelines_2013.pdf.

[21] Surabhi Mittal, Sanjay Gandhi and Gaurav Tripathi. (2010). "Socio-Economic Impact of Mobile Phones on Indian Agriculture." Indian Council for Research on international Economic Relations, $1-53$.

http://www.eaber.org/sites/default/files/documents/Socioeconomic\%20Impact\%20of\%20Mobile\%20Phones\%20on\%20Indian\%20Agriculture.pdf

[22] Anne Moorhead. (2005). "Country Profile-Botswana." http://www.new-ag.info/en/country/profile.php?a=845.

[23] Statistics Botswana. (2013). "Annual Agricultural Survey Report, 2013.” http://www.cso.gov.bw/images/agricreport2013.pdf.

[24] LeoVan Audenhove, L. (2003). "Towards an integrated information society policy in South Africa: an overview of political rhetoric and policy initiatives 1994-2000." Communication, 29:1-2, 129-147, DOI: 10.1080/02500160308538024

*Corresponding author.

E-mail address: tpholele@bca.bw 